Time Disciplined Non-PLL Active Synchronization for Grid Forming Inverters

Toby Meyers

Texas Power and Energy Conference 2021

February 2-5, 2021 


\section{Project Breakdown}

1. Grid Forming Inverters (GFMIs) [1]

- Critical to providing stability for weak systems (high percent GFLI, microgrids, ...).

2. Active Synchronization [2]

- With a DQ inverter, we can separate voltage and phase.

- Phase is the key to synchronization.

3. Non-PLL [3] (Phase-Lock Loop)

- PLLs are inaccurate in weak grids and computationally burdensome.

- Solution is relying entirely on the internal clock and not the grid.

4. Time Disciplined [4]

- With a reliance on phase, we need to have a solid phase reference. 


\section{Metrics from Existing Standards}

\section{TABLE I}

IEEE 1547 Relevant Metrics [5]

\begin{tabular}{c|c|c} 
Requirement & Limit & Section of IEEE 1547-2018 \\
\hline \hline Absolute Voltage & $0.7-1.1 \mathrm{PU}$ & 6.4 \\
\hline Absolute Frequency & $58.5-61.2 \mathrm{~Hz}$ & 6.5 \\
\hline $\begin{array}{c}\text { ROCOF } \\
\text { (Ride Through) }\end{array}$ & $0.5 \mathrm{~Hz} / \mathrm{sec}$ & 4.5 .2 .5 \\
\hline Enter Service & $\begin{array}{c}0.917-1.05 \mathrm{PU} \mathrm{Voltage} \\
59.5-60.1 \mathrm{~Hz}\end{array}$ & 4.10 .4 \\
\hline $\begin{array}{c}\text { Reconnection Tolerances } \\
\text { (with respect to the Grid) }\end{array}$ & $\begin{array}{c}0.1 \mathrm{~Hz} \text { Frequency } 59.9-60.1 \mathrm{~Hz}) \\
3 \% \text { PU Voltage } \\
10^{\circ} \text { phase }\end{array}$ & 7.4 \\
\hline Initial Grid Synchronization & $\begin{array}{c}\text { Maximum EPS Line Voltage } \\
138 \% \text { for }<1 \text { cycle }\end{array}$ &
\end{tabular}

TABLE II

IEEE 1547.4 MODE COMPARISON

\section{[6]}

\begin{tabular}{c|c|c} 
Framework Mode & IEEE 1547.4-2011 Mode & Section of IEEE 1547.4-2011 \\
\hline \hline Reconnection Coordination & Reconnection Mode & 4.4 .4 \\
\hline \multirow{2}{*}{ Ride Through } & Area EPS-connected Mode (normal parallel operation) & 4.4 .4 \\
& Transition-to-Island Mode & 4.4 .2 \\
& Island Mode & 4.4 .3
\end{tabular}




\section{Synchronization Modes}

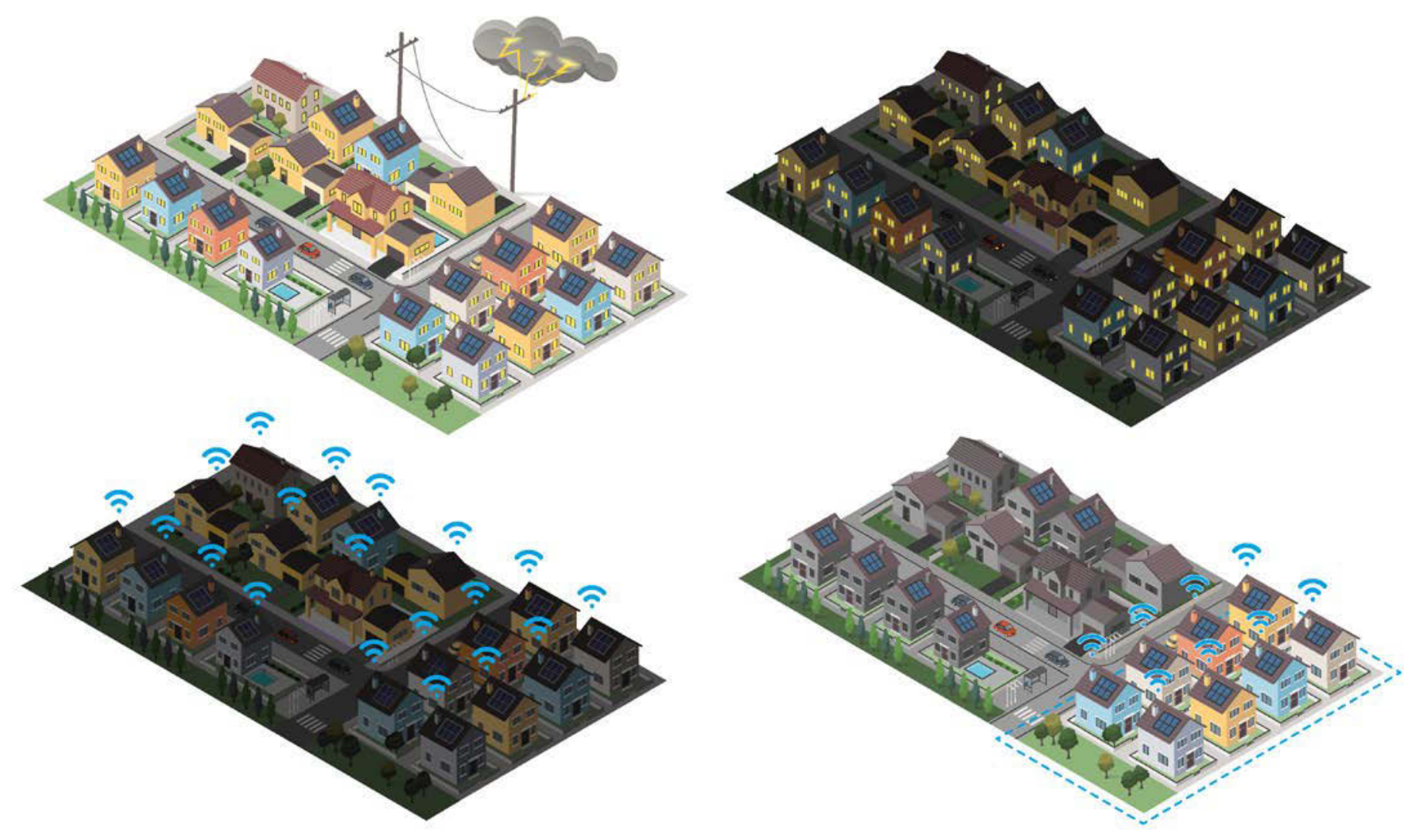




\section{Inverter Model}
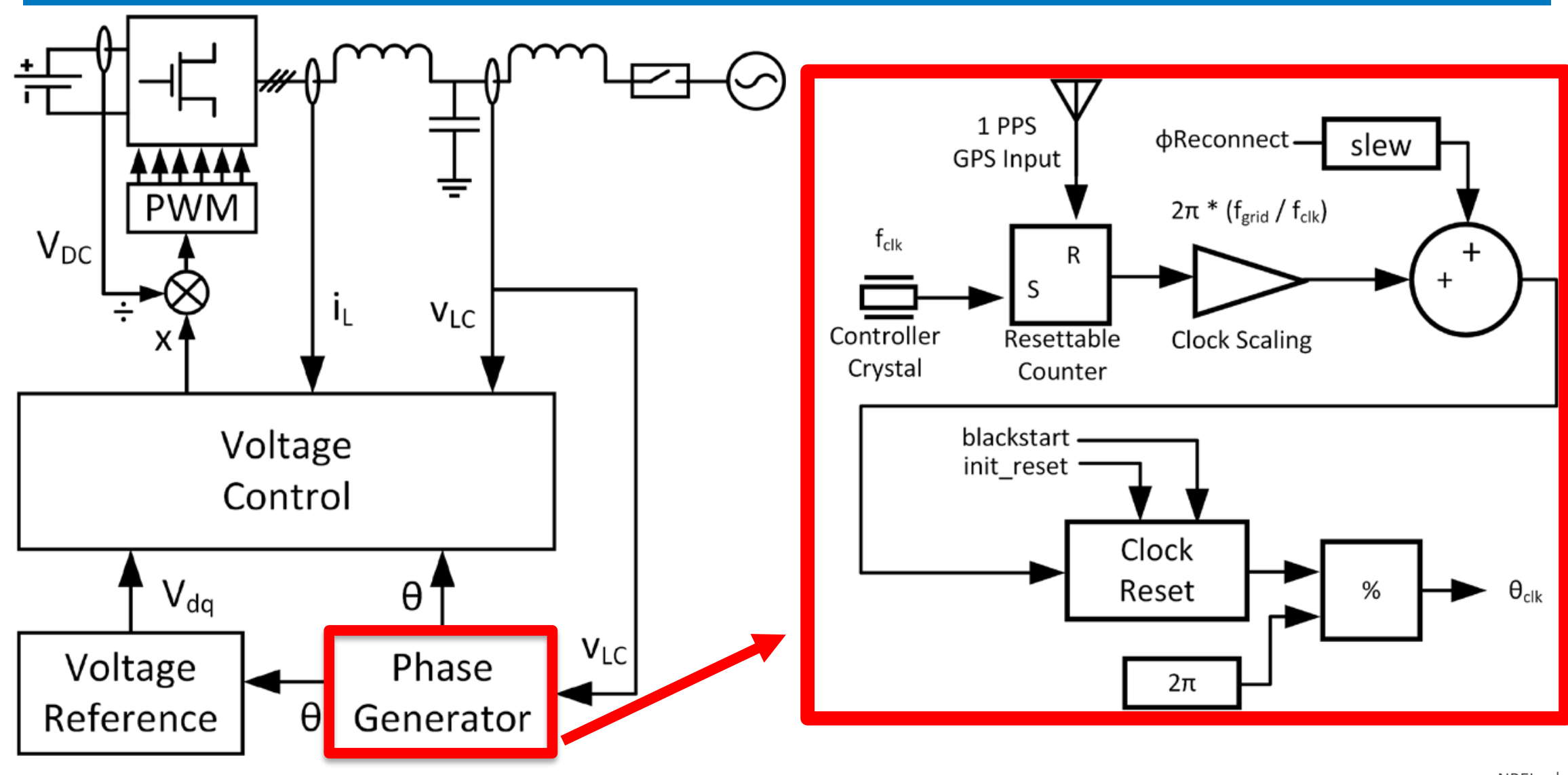


\section{Simulation Results - Frequency/ROCOF}

Initialization, Islanding, Reconnection (Grid)

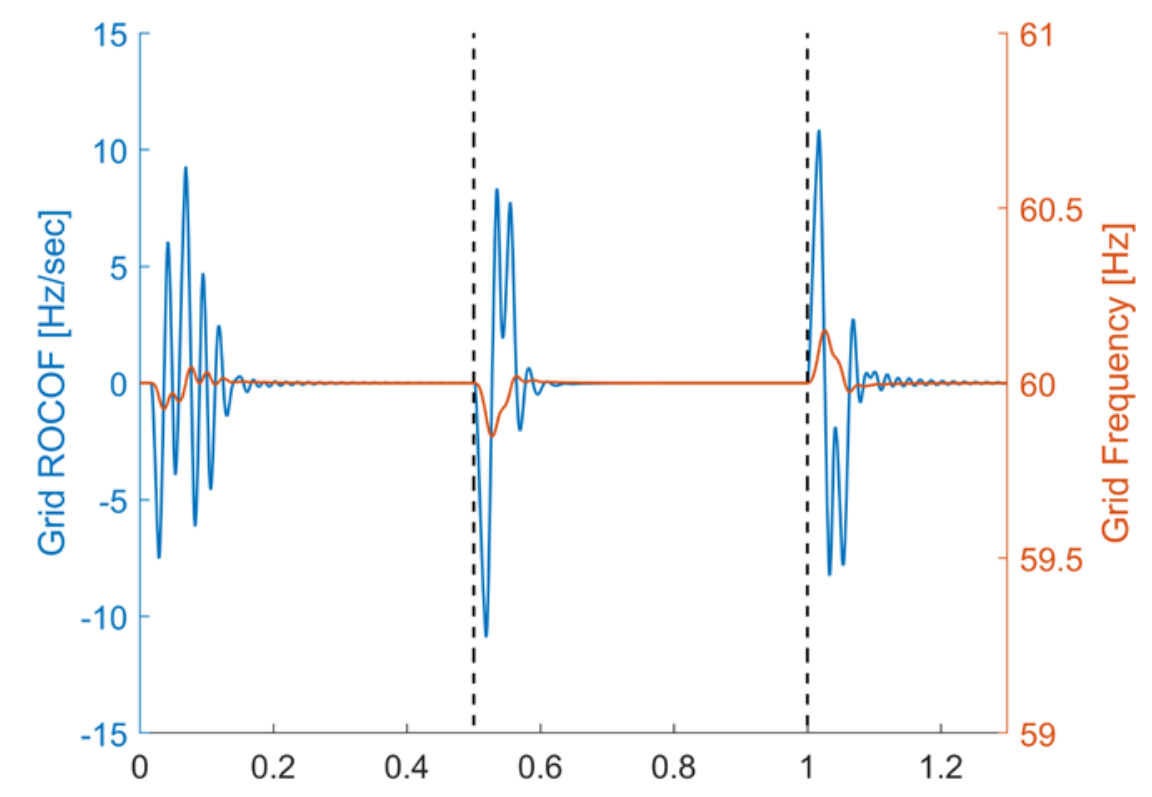

Blackstart (Inverter)

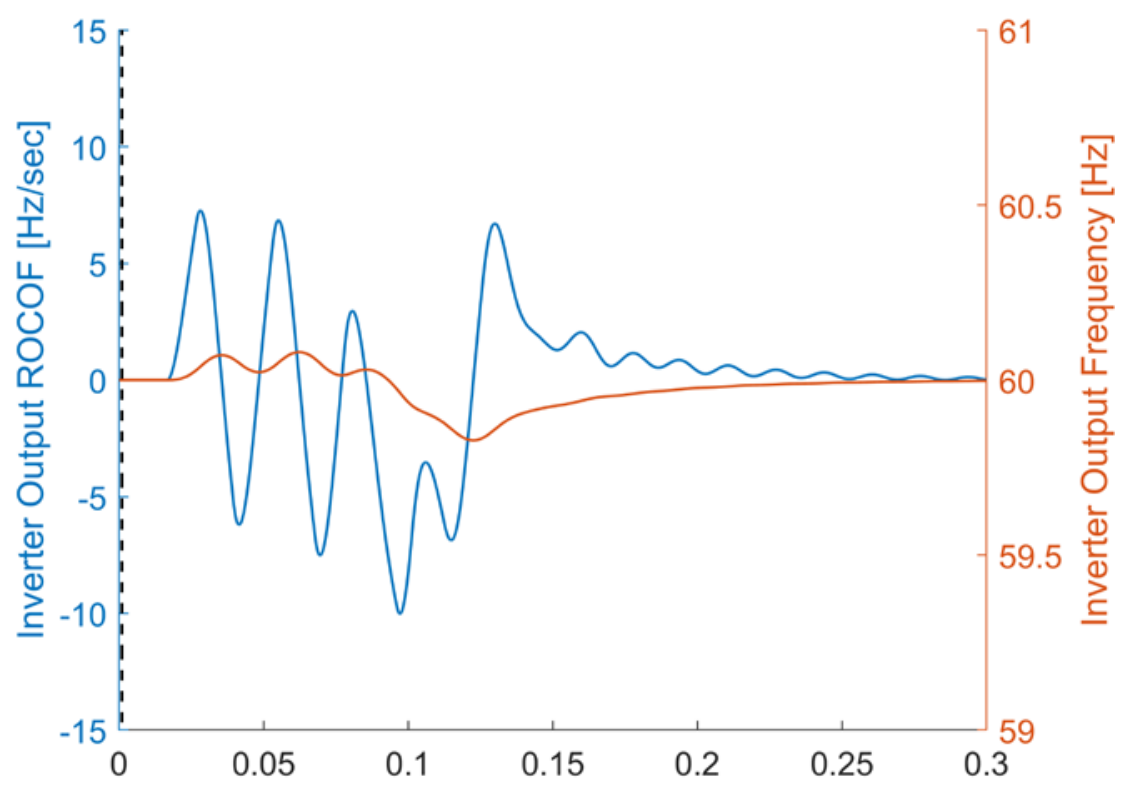




\section{Simulation Results - Summary Table}

TABLE IV

Simulation RESUlTS SUMMARY

\begin{tabular}{c|c|c|c|c} 
Category/Measurement & Min Frequency [Hz] & Max Frequency [Hz] & Min ROCOF [Hz/sec] & Max ROCOF [Hz/sec] \\
\hline \hline Initialization (Inverter) & 59.79 & 60.18 & -12.81 & -7.523 \\
\hline Initialization (Grid) & 59.92 & 60.05 & -12.51 & 9.278 \\
\hline Ride Through (Inverter) & 59.56 & 60.01 & -10.89 & 13.04 \\
\hline Ride Through (Grid) & 59.85 & 60.02 & -13.02 & 8.336 \\
\hline Reconnection (Inverter) & 59.94 & 60.38 & -8.252 & 12.52 \\
\hline Reconnection (Grid) & 59.97 & 60.15 & -9.996 & 7.85 \\
\hline Blackstart (Inverter) & 59.83 & 60.08 &
\end{tabular}




\section{References}

[1] P. Denholm, T. Mai, B. Kroposki, R. Kenyon, and M. O'Malley, Inertia and the Power Grid: A Guide Without the Spin. No. NREL/TP-6A20-73856, National Renewable Energy Laboratory, Golden, CO, May 2020.

[2] J. Wang, A. Pratt, and M. Baggu, "Integrated synchronization control of grid-forming inverters for smooth microgrid transition," in 2019 IEEE Power and Energy Society General Meeting (IEEE PES GM), pp. 1-5, Aug. 2019.

[3] J. Wang, B. Lundstrom, and A. Bernstein, "Design of a non-pll grid forming inverter for smooth microgrid transition operation," in 2020 IEEE Power and Energy Society General Meeting (IEEE PES GM), Aug. 2020.

[4] M. S. Golsorkhi, M. Savaghebi, D. D. Lu, J. M. Guerrero, and J. C. Vasquez, "A GPS-based control framework for accurate current sharing and power quality improvement in microgrids," in IEEE Transactions on Power Electronics, vol. 32, pp. 5675-5687, July 2017.

[5] "IEEE standard for interconnection and interoperability of distributed energy resources with associated electric power systems interfaces," IEEE Std. 1547-2018, Apr. 2018.

[6] "IEEE guide for design, operation, and integration of distributed resource island systems with electric power systems," IEEE Std. 1547.4-2011, July 2011. 


\section{Thank You}

\section{Toby.Meyers@nrel.gov}

\section{www.nrel.gov}

NREL/PR-5D00-78901

This work was authored by the National Renewable Energy Laboratory (NREL), operated by Alliance for Sustainable Energy, LLC, for the U.S. Department of Energy (DOE) under Contract No. DE-AC36-08GO28308. This work was supported by the Laboratory Directed Research and Development (LDRD) Program at NREL. The views expressed in the article do not necessarily represent the views of the DOE or the U.S. Government. The U.S. Government retains and the publisher, by accepting the article for publication, acknowledges that the U.S. Government retains a nonexclusive, paid-up, irrevocable, worldwide license to publish or reproduce the published form of this work, or allow others to do so, for U.S. Government purposes. 


\section{Backup Slides}




\section{Initialization Phase Generator}

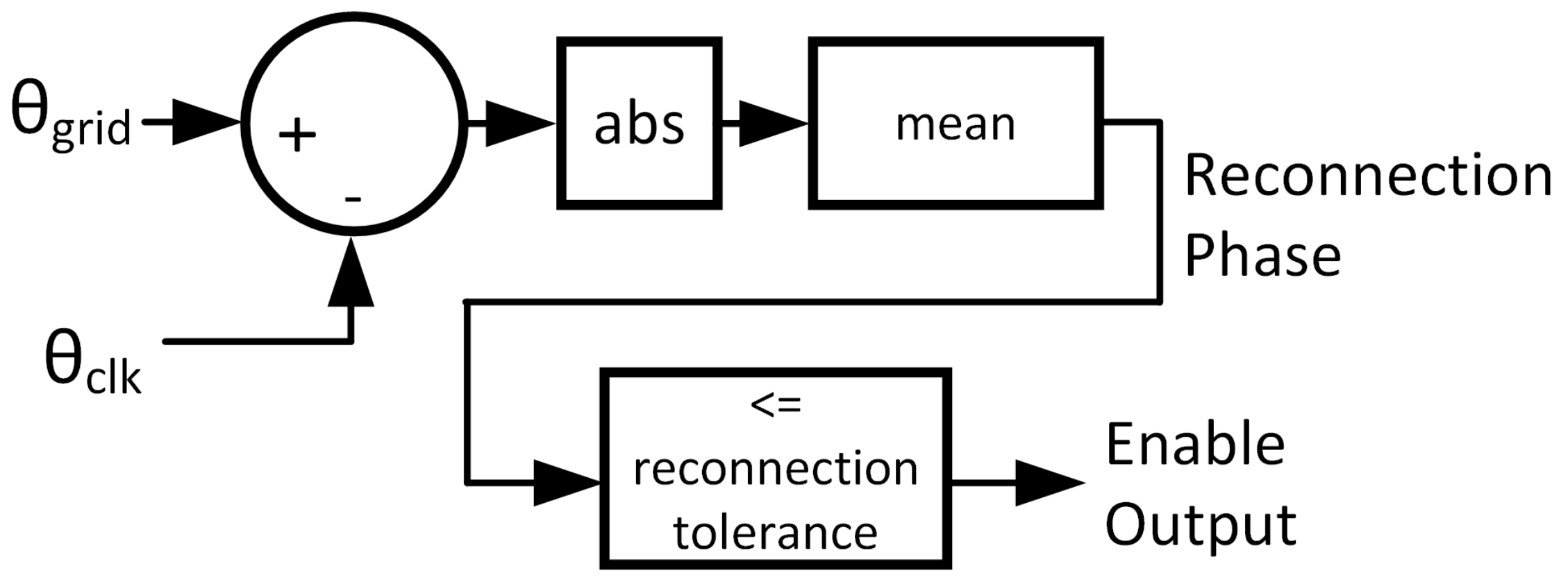




\section{Reconnection Phase Generator}

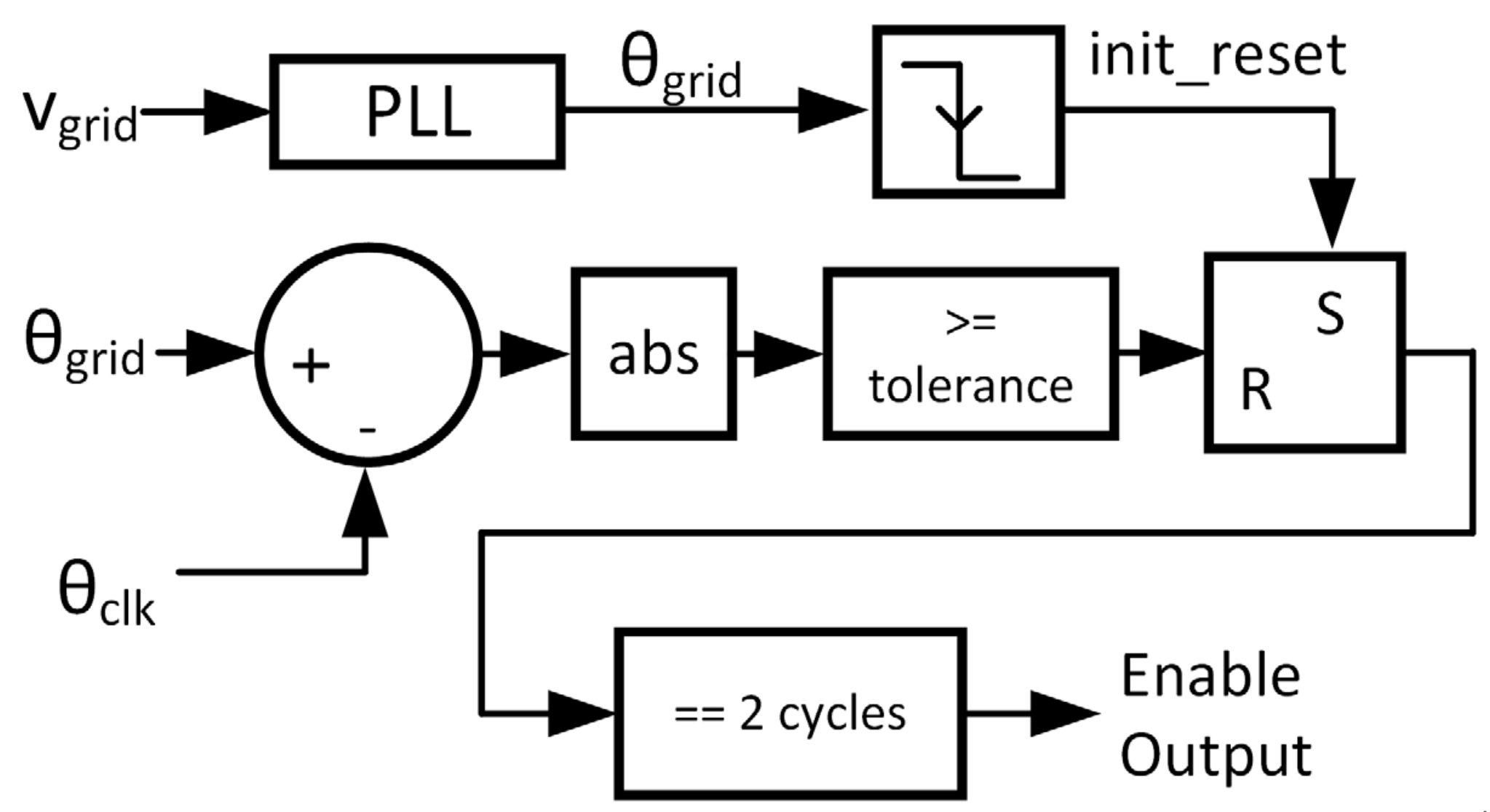




\section{Simulation Results - Voltages}

Initialization

(Inverter)

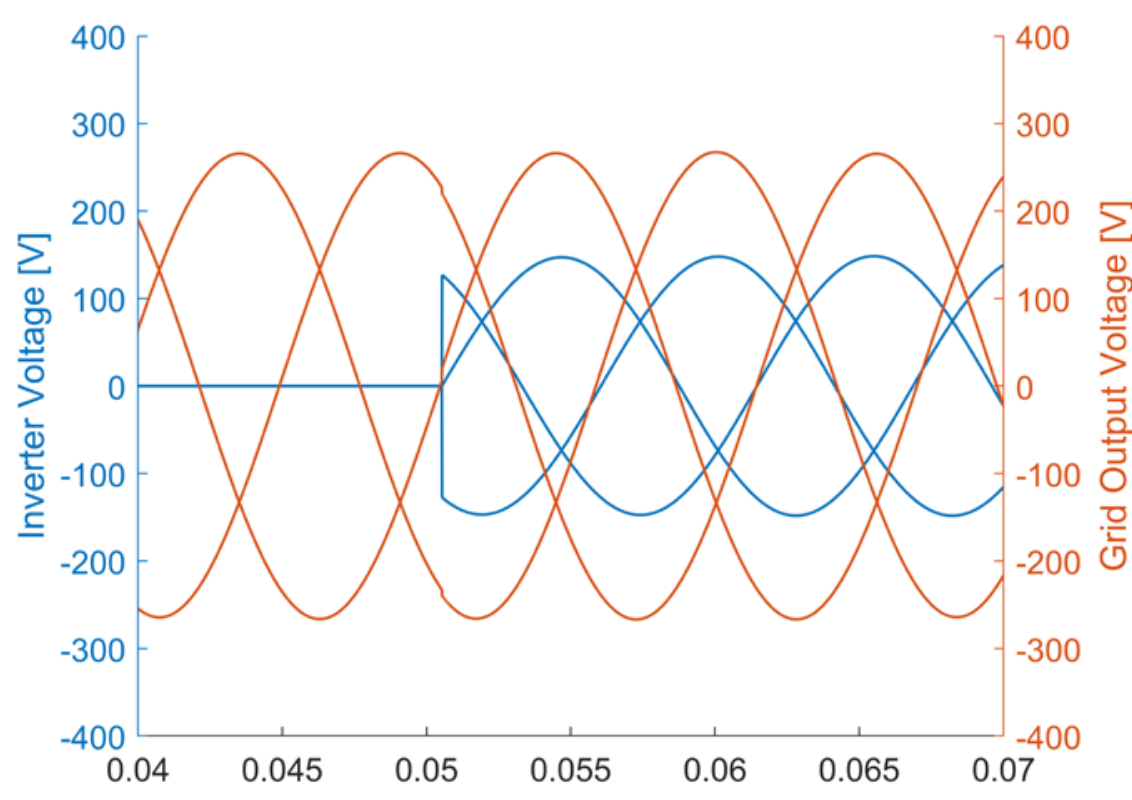

Reconnection

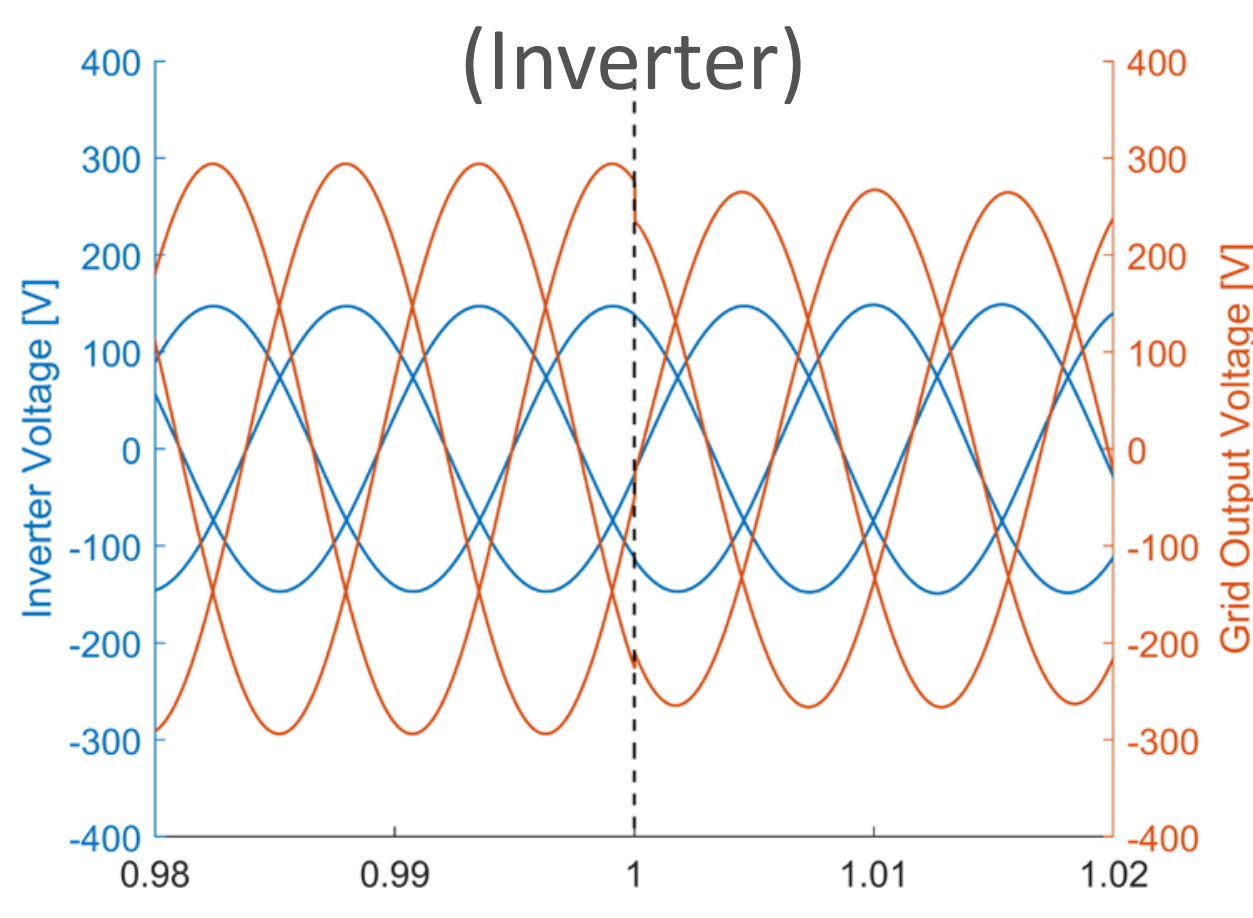




\section{Simulation Results - Voltages (Cont.)}

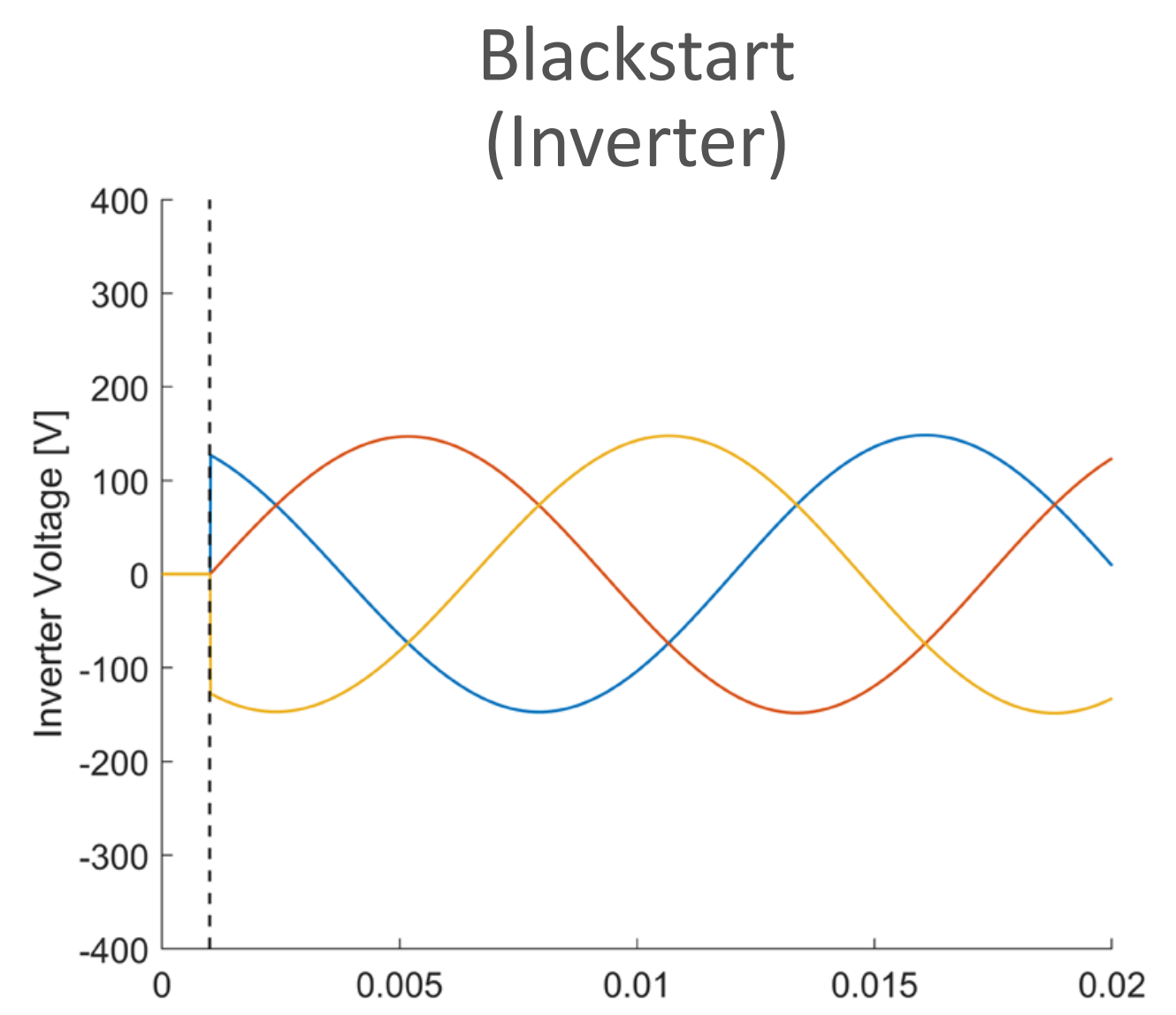


Simulation Results - Frequency (Inverter)

Initialization, Islanding, Reconnection (Inverter)

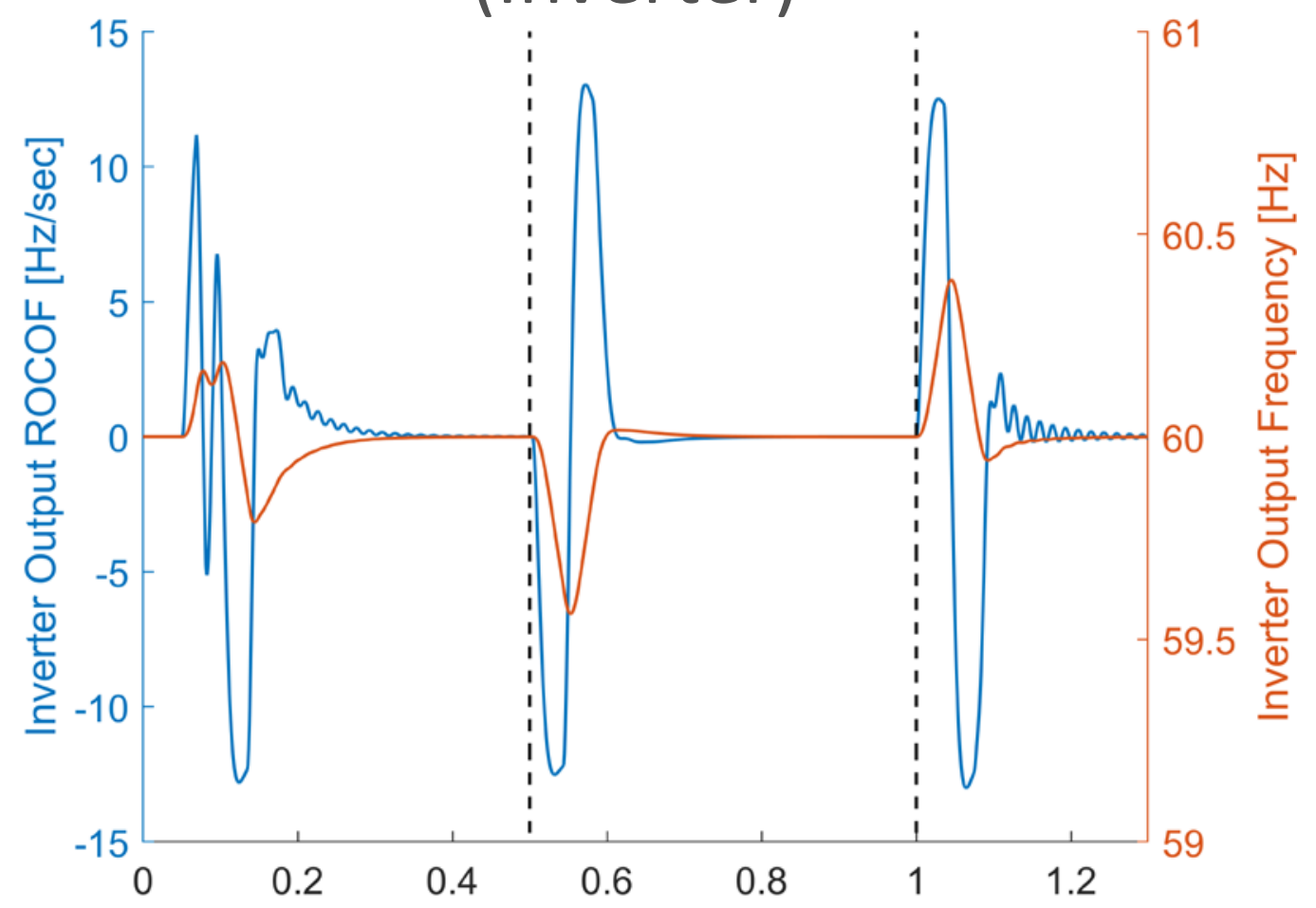

